\section{Collagen/Povidone as a New Endoscopic Treatment Option in Peptic Ulcer Bleeding}

We report here on a case of recurrent bleeding secondary to duodenal ulcer, despite previous endoscopic treatment with epinephrine and argon, which was controlled with endoscopic injection of collagen/povidone. This is a biological agent derived from gamma-irradiation of a mixture of type I pepsinated porcine collagen and povidone that has been reported to improve recovery during the healing process $[1,2]$.

A 63-year-old man with history of chronic use of nonsteroidal anti-inflammatory drugs presented with hematemesis and melena. Endoscopic examination revealed a large ulcer in the second portion of the duodenum, with two visible vessels, which were sclerosed with $1: 10000$ epinephrine and argon. Nine days after this procedure, the patient had a new bleeding event, with the same endoscopic features (Figure $\mathbf{1}$ ), and received the same treatment. Hemoclips were not used, as almost the entire surface of the extensive lesion was thickened and bleeding, so that clips could not be attached. After 2 days, in view of continuing bleeding, it was decided to administer $4 \mathrm{ml}$ of collagen/ povidone in $10 \mathrm{ml}$ of distilled water through the endoscope, injecting $3 \mathrm{ml}$ into the lesion and $7 \mathrm{ml}$ on the surface. Significant improvement in the lesion was observed $24 \mathrm{~h}$ after the collagen/povidone injection (Figure 2 ). Notable healing was evident $72 \mathrm{~h}$ later, and there was no subsequent bleeding.

In this particular case, collagen-povidone proved to be a good treatment option, and controlled studies of it as a new sclerosant agent may be worth considering.
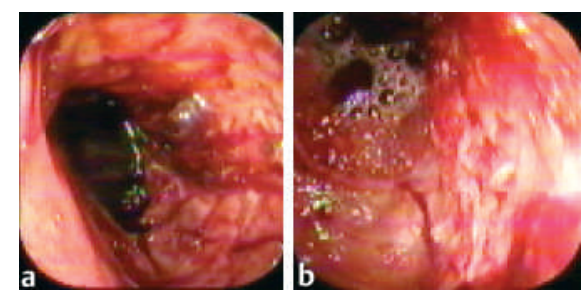

Figure 1 a Recurrent bleeding, b sclerosed with epinephrine and argon.
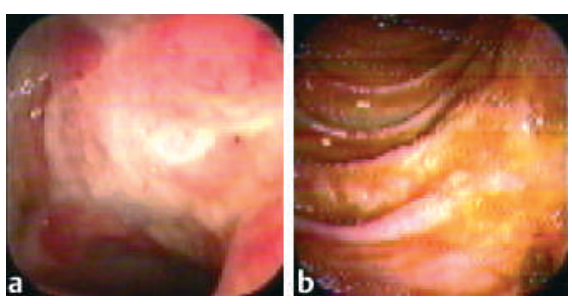

Figure 2 a, b The endoscopic appearance $24 \mathrm{~h}$ after treatment with collagen-povidone.

\section{A. de Hoyos' ${ }^{1}$, M. A. Monroy ${ }^{1}$, G. Checa ${ }^{2}$, P. Rodriguez ${ }^{1}$}

${ }^{1}$ Dept. of Gastroenterology, Angeles del Pedregal Hospital, Mexico City, Mexico

2 Dept. of Anesthesiology, Angeles del Pedregal Hospital, Mexico City, Mexico
References

${ }^{1}$ Almazán DA, De la Cruz GJC, Lira RJM et al. Investigación experimental de la regeneración ósea en fémures de rata después de la aplicación de cólagena I polimerizada: estudio radiológico, histológico e histoquímico. Rev Mex Ortop Traum 1996; 10: 142 - 152

${ }^{2}$ Krötzsch-Gomez FE, Furuzawa-Carballeda J, Reyes-Marquez R et al. Cytokine expression is downregulated by collagen-polyvinylpyrrolidone in hypertrophic scars. J Invest Dermatol 1998; 111: $828-834$

\section{Correspondling Author}

\section{A. de Hoyos, M.D.}

Camino a Santa Teresa No 1055-119

Col. Héroes de Padierna

Deleg. Magdalena Contreras

10700 Mexico City

Mexico

Fax: $\quad+52-55-55688946$

E-mail: andehoyos@yahoo.com 